\title{
DYSPHAGIA PNEUMONITIS
}

The inhalation of infected matter, food and foreign bodies from the mouth and nasopharynx is a common cause of pneumonia, lung abscess, atelectasis and bronchiectasis. Inhalation of stomach contents sometimes occurs during vomiting under anaesthesia, during acute alcoholism or in states of great debility. It is very probable that infants occasionally inhale small quantities of regurgitated milk, especially when asleep in the recumbent position.

The inhalation of oesophageal contents frequently occurs in conditions of dysphagia. Belcher (1949) collected and analysed 48 cases of the syndrome he called dysphagia pneumonitis in which he included all pulmonary aspiration phenomena associated with mechanical dysphagia, but excluded those due to central dysphagia and bronchooesophageal fistulae: 34 were due to achalasia of the cardia, 5 to pharyngeal diverticla, 3 to carcinoma of the oesophagus and 6 to oesophageal strictures of various types.

The present report concerns a case of dysphagia pneumonitis due to achalasia and demonstrates two common aspects of the contition, namely lung abscess and fibrosis.

\section{Case Report}

A man aged 42 complained of difficulty in swallowing for 20 years. Recently this had become worse and solids could only be swallowed if chased down with large quantities of fluid. Eight years previously his chest had been X-rayed after an attack of catarrhal jaundice which had left him debilitated and with a slight cough. Right upper lobe infiltration and a large cavity were found (Fig. I) and a diagnosis of pulmonary tuberculosis was made. The sputum was persistently negative for tubercle bacilli. A right artificial pneumothorax was induced and he was admitted to a sanatorium where he stayed for two years. The artificial pneumothorax was abandoned.

He thereafter remained well for six years when, concurrently with the increased dysphagia, his cough returned and was accompanied by the onset of pain in the left side of his chest. He had recently been unable to sleep lying flat as this posture brought on incessant coughing and he had taken to sleeping propped up with pillows.

On examination he was a fit-looking but thin man; there was no clubbing and there were few added sounds in the chest. The X-ray showed right upper lobe fibrotic changes and left midzone pneumonitis and pleural reaction (Fig. 2); it also suggested the presence of a dilated oesophagus. Tomographs did not show cavitation. The B.S.R. was 38 and vital capacity 3,100 ; the sputum was persistently negative for tubercle bacilli. A barium swallow confirmed the presence of achalasia of the cardia with a grossly dilated oesophagus (Fig. 3).

A diagnosis of dysphagia pneumonitis due to achalasia was made and Heller's operation performed. This was followed almost immediately by a return of the ability to swallow normally and by a radiological diminution in the size of the oesophagus (Fig. 4). $\mathrm{He}$ has remained well during the following nine months and there has been no return of cough; he sleeps lying down.

\section{Discussion}

Bronchial aspiration of oesophageal contents is especially likely to occur if the cough reflex or the protective reflex which closes the glottis on swallowing is impaired. This may account for the frequency with which carcinoma of the upper third of the oesophagus is complicated by aspiration pneumonia, since in this condition the recurrent laryngeal nerves are often involved. The resulting vocal cord paralysis also severely impairs the cough mechanism.

Aspiration leading to dysphagia pneumonitis may occur in the absence of such complications and, in fact, the patient's general health may be good, as in the present case.

Belcher (1949) pointed out that even in advanced cases of mega-oesophagus due to achalasia the column of fluid seldom reaches the glottis when the patient is in the upright position and that aspiration is only likely to occur in recumbency and during sleep. It is possible that the protective reflexes become less sensitive than normal due to repeated small stimuli and ultimately allow aspiration to take place; sleep further depresses the reflexes. The history in the present. case 


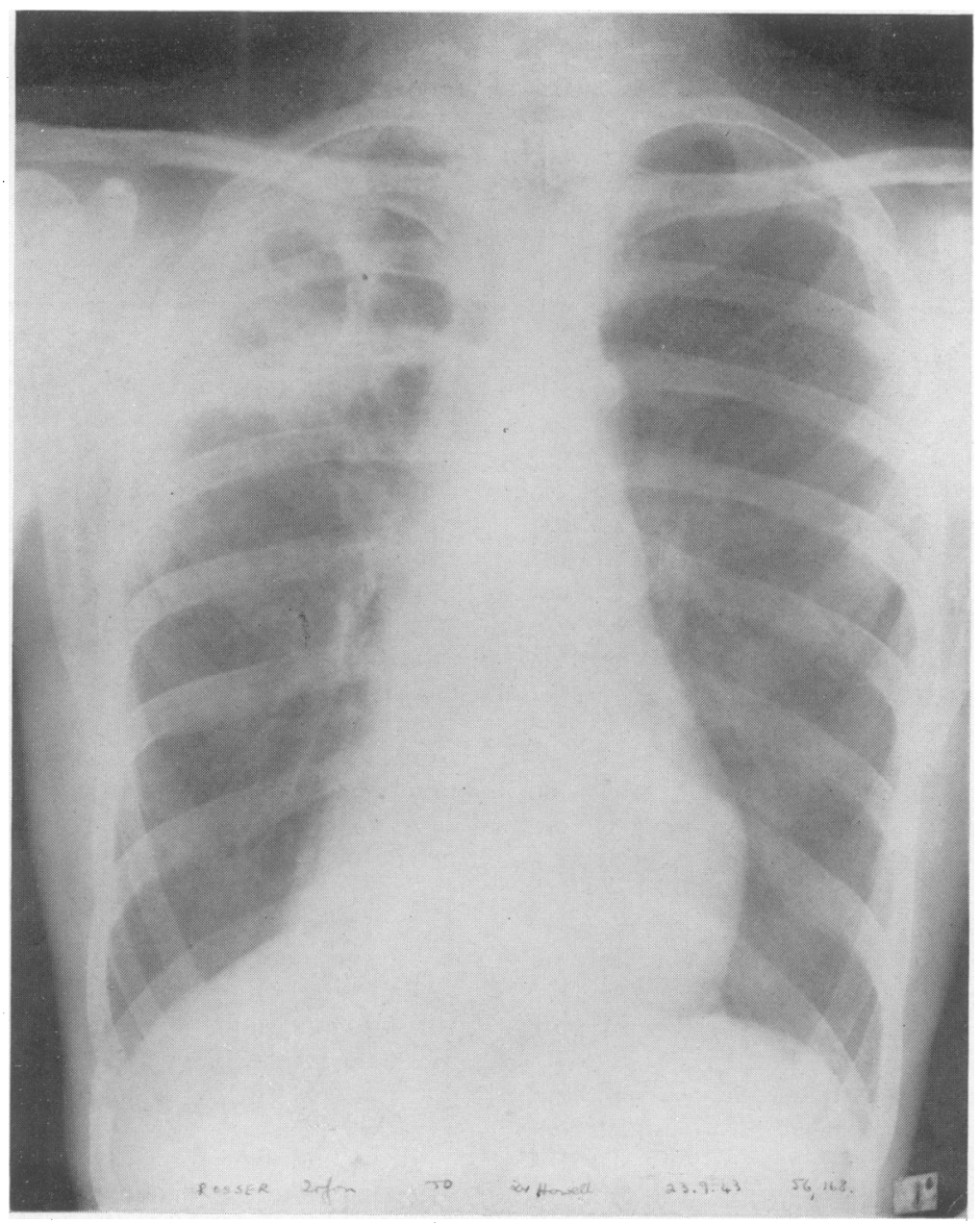

Plate I (1943).-Right upper lobe pneumonitis with cavitation.

suggests that aspiration did in fact occur during sleep in the recumbent position, since the patient was continually awakened by cough and finally took to sleeping propped up.

In Belcher's series the pulmonary lesions produced by aspiration were:

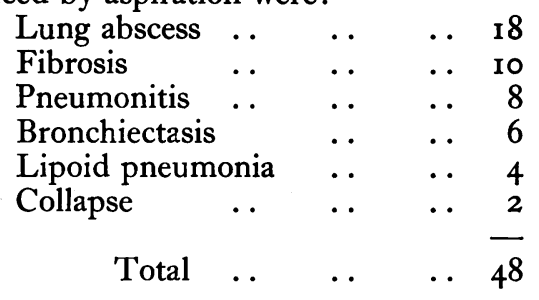

Tracheo-bronchitis is probably present in addition in every case and may cause a persistent irritating cough before there is any radiological evidence of aspiration.
The lesions can occur in any part of the lungs but the upper lobes and the apices of the lowe lobes, which are the areas to which aspirated material most frequently gravitates when the patient is lying down, appear to be most affectedo In the present case the abscess occurred in the right upper lobe where the pneumonitis and fibrosis were also most marked. Some pneumo nitis was demonstrated in the left mid-zone and was probably the cause of the pleurisy resulting in the left-sided chest pain.

\section{Diagnosis}

In most instances the diagnosis of dysphagi pneumonitis should present little difficulty if the possibility is kept in mind. In some cases, how ever, the dysphagia is almost 'silent' and the् symptoms are not mentioned unless the patien is questioned directly. In the present case the 


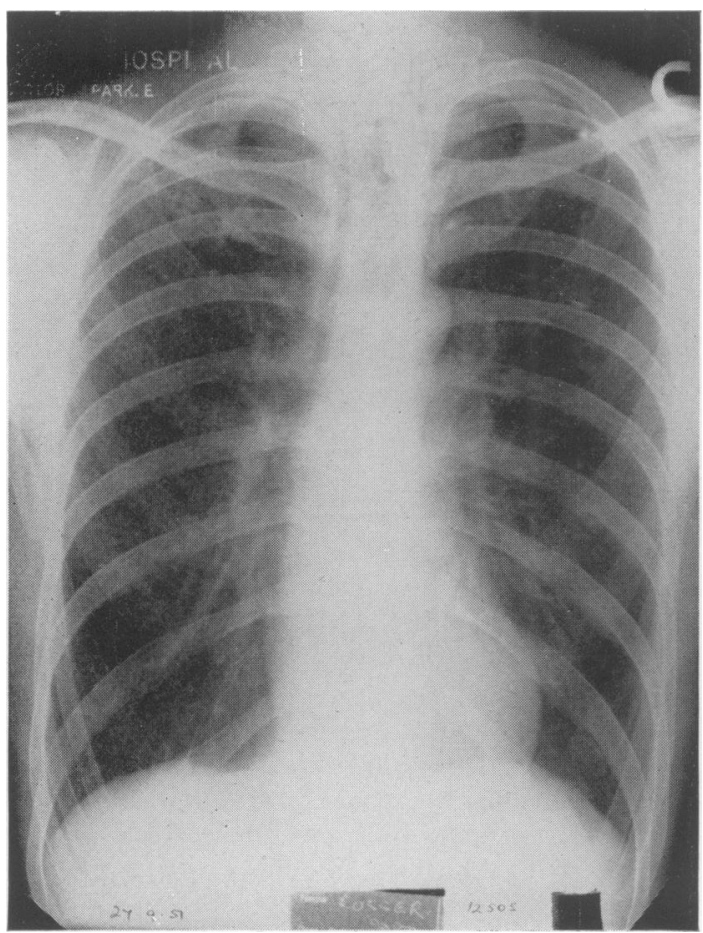

Plate 2 (1950).-Right upper lobe fibrosis. Left midzone pneumonitis and pleural reaction; there has been considerable broadening of the mediastinal shadow since 1943 .

radiological picture origin:lly suggested pulmonary tuberculosis and, although there was a history of dysphagia, its association with the pulmonary lesion was not realized at that time. Apparent confirmation of the diagnosis of pulmonary tuberculosis might well have been obtained, since it is not uncommon for non-tuberculous acid-fast bacilli to be present in the oesophageal contents and sputum in dysphagia pneumonitis. The bacilli are non-pathogenic, but unless this fact is established their presence in the sputum may give rise to considerable diagnostic difficulty.

\section{Summary}

A case of dysphagia pneumonitis due to achalasia of the cardia is reported.

The mechanism of aspiration, the lesions produced and the diagnosis are briefly discussed.

I wish to thank Mr. Vernon C. Thompson for permission to publish this case and Prof. C. G. Rob for valuable criticism.

\section{London Chest Hospital.}

$$
\text { W. H. HeLM, M.R.C.P. }
$$

\section{BIBLIOGRAPHY}

BELCHER, J. R. (1949), Thorax, 4, 44.

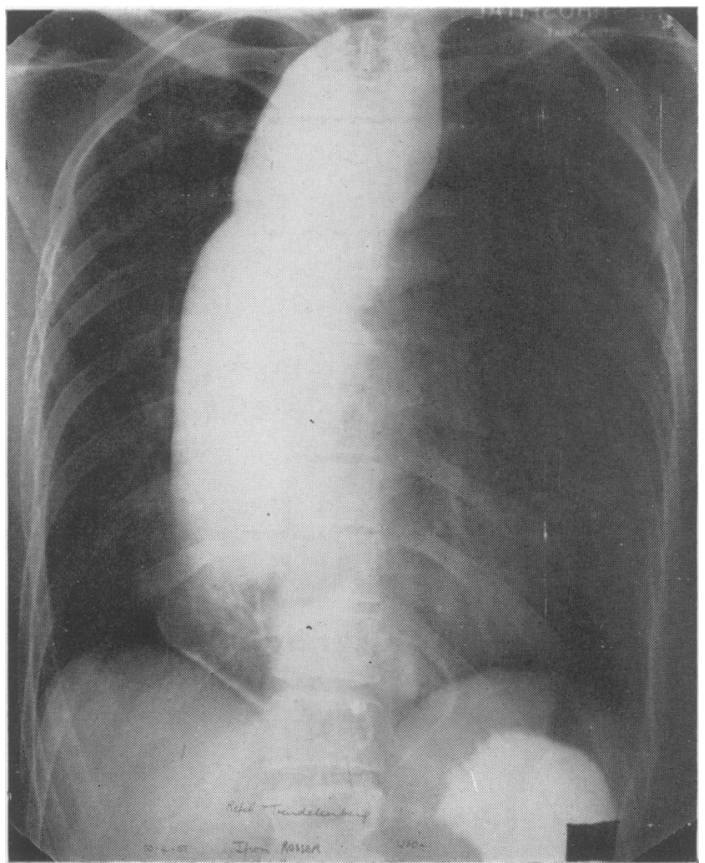

Plate 3.-Barium meal showing greatly dilated oesophagus forming the right border of the widened mediastinal shadow seen in Plate 2.

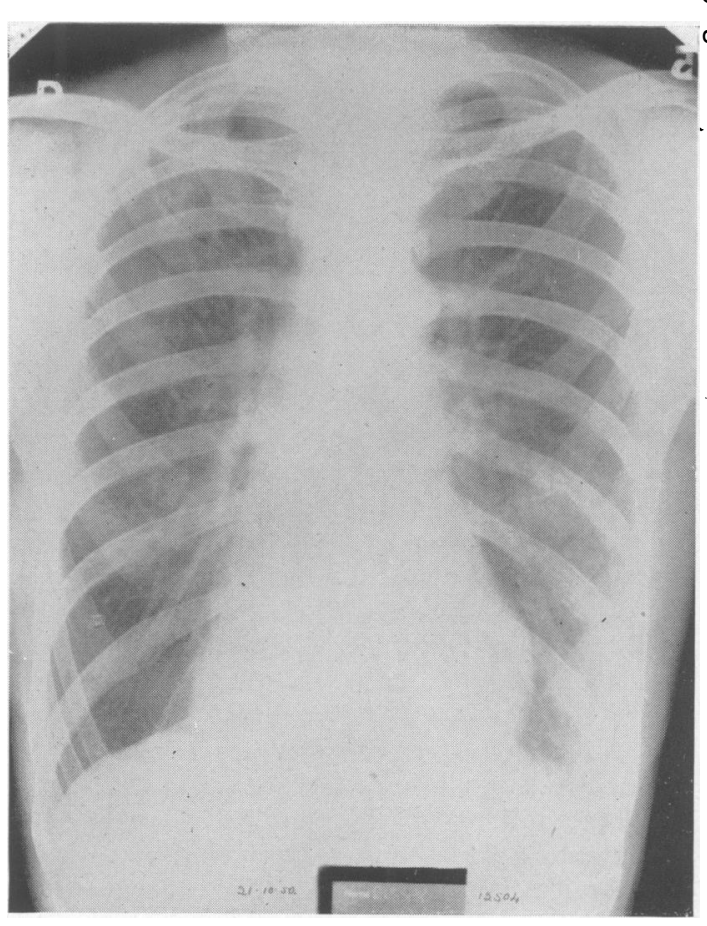

Plate 4.-Five months after Heller's operation. The mediastinal shadow is now normal. The right upper lobe shows fibrosis; the left mid-zone infiltration and pleural reaction have cleared, 